\title{
EL SACRIFICIO GLADIATORIO Y SU VINCULACIÓN CON LA GUERRA EN LA SOCIEDAD MEXICANA
}

\section{GLADIATORIAL SACRIFICE AND ITS CONNECTION WITH WAR IN MEXICAN SOCIETY}

POR

\author{
ISABEL Bueno BRAVo*
}

\section{RESUMEN - Abstract}

El siguiente trabajo analiza cómo el Estado azteca-mexica rentabilizó el éxito de la guerra a través de las ceremonias públicas, centrándose en la fiesta de tlacaxipehualiztli, una de las más importantes del calendario, donde se daban cita los gobernantes de las provincias más poderosas, así como millones de personas venidas de todos los rincones del Anahuac. Este era el momento propicio para que el imperio desplegara toda su propaganda e hiciera ostentación de su poder. Era el lado oscuro de la conquista, sangre y arena o parafraseando a Juvenal panem et circenses.

The following work analyzes how the Mexica State promoted the success of war through public ceremony and focuses on the celebration of Tlacaxipehualiztli. As was one of the most important ceremonies of the year, it was where the most powerful provincial leaders as well as millions of people from all corners of the Anahuac met. This was a favourable moment for the empire to display all of its propaganda and flaunt its power. It is the dark side of conquest, of blood and sand, or as paraphrased by Juvenal, panem et circus.

\section{Palabras Clave - Keywords}

Guerra; espectáculo; beneficio; poder y masa.

War; spectacle; benefit; power and people.

\section{LA GUERRA EN MESOAMÉRICA EN ÉPOCA MEXICA}

Cuestiones como la guerra, sus beneficios, ética y violencia son siempre polémicas. Intentar analizarlas en sociedades que guardan una distancia temporal permite un estudio más desapasionado y, quizá, menos hipócrita. A través de la guerra se puede conocer cualquier sociedad prácticamente al completo, porque está presente en el arte, la educación, la economía, la religión, las relaciones sociales y, naturalmente, en la política. A pesar de su valiosa aportación no es un tema al que se le haya prestado demasiada atención, sobre todo en la sociedad prehispánica.

\footnotetext{
* Doctora por la Universidad Complutense de Madrid. E-mail: ibuenob@terra.es.
} 
Uno de los motivos principales para desanimar en su conocimiento estriba en la carencia de información sobre la materia. Sin embargo, el estudio de las fuentes mesoamericanas, con ojos críticos, desvela un apasionante, complejo y desconocido mundo bélico. La mayoría describen a la sociedad mexica y, por lo tanto, los datos que proporcionan se centran en ella porque, como heredera de la vasta tradición mesoamericana, está en disposición de ofrecernos las claves que permiten desentrañar los entresijos de la guerra en Mesoamérica, reconociendo, no obstante, las peculiaridades de cada comunidad derivadas de su organización política y su desarrollo cultural.

En el presente trabajo analizaremos cómo el Estado mexica rentabilizaba el éxito de la guerra a través de las ceremonias públicas. La más celebrada era la fiesta de tlacaxipehualiztli, o sacrificio gladiatorio, aunque antes se impone un rápido recorrido por las características generales de la guerra para contextualizar la ceremonia.

La declaración de la guerra correspondía al gobernante o tlatoani, que, tras haberse reunido con su Consejo, enviaba mensajeros, quaquauhnochtzin, a la provincia objetivo para avisar de sus intenciones hostiles. Ésta tenía dos opciones: quedar bajo la órbita mexica sin luchar y aceptar, por la vía diplomática, la imposición del tributo o recoger el guante y combatir. En este caso el tlatoani hacía un llamamiento público a los barrios o calpulli que tenían sus escuadrones listos para la batalla.

Cuando Tenochtitlan, la capital del imperio azteca, rescató su independencia de Azcapotzalco en 1428 las estructuras de poder empezaron a fortalecerse gracias a un elaborado programa ideológico que se inculcaba desde la escuela. Se estableció que cada calpulli tuviera un telpochcalli sufragado por el gobierno, al que todos los jóvenes de alrededor de 15 años tenían la obligación de asistir. Bajo la supervisión de los veteranos, los jóvenes aprendían todo lo relacionado con la guerra y el manejo de las armas. Se preparaban para combatir en escenarios terrestres y navales - muchas de las ciudades estaban ubicadas a orillas de los lagos y otras en los mismos lagos - , con el incentivo que proporcionaba la posibilidad de recompensas materiales y, lo que era más importante, el prestigio social.

Por su trascendencia se reglamentaron todos los aspectos de la institución militar, tenían sus propios tribunales y jueces para juzgar asuntos castrenses tales como la deserción, la traición, el uso indebido de uniformes o divisas, la apropiación de cautivos, etc. Esta última cuestión era relevante porque, en función del número de prisioneros y de si se habían conseguido con el esfuerzo individual o colectivo, se ascendía en el escalafón militar. Y esto, a su vez, tenía enormes repercusiones sociales y de movilidad dentro del grupo; por eso, si había duda sobre a quién pertenecía un prisionero, en juicio solemne se hacían averiguaciones en las que se citaba al propio cautivo.

Tras haber consultado los sacerdotes el día propicio para iniciar la guerra, los escuadrones partían bajo el símbolo de su estandarte (fig. 1). Por el camino se sumaban las tropas auxiliares que aportaban algunos pueblos sometidos, mientras otros, que estaban en la ruta, preparaban agua y víveres para alimentar a la tropa. Tanto el aporte humano como el alimentario eran parte de sus obligaciones tributarias.

Los motivos para declarar la guerra eran variados: satisfacer el honor, la defensa del territorio, etc. Pero lo que subyacía detrás de cada acto bélico eran los intereses económicos. En Mesoamérica dos rasgos lo confirman: por un lado, los asentamientos estaban muy cercanos y superpoblados, esto les obligaba a acudir a los mismos nichos ecológicos; y, por otro, el desarrollo del comercio. La necesidad de controlar ambos llevó al Estado a protegerlos a través del ejército, y así economía y política quedaban vinculados con la institución militar.

Ejército, economía y política formaban un paquete envuelto con los colores de la religión, que se encargaba de apoyar y difundir la ideología que el Estado generaba. En la sociedad 


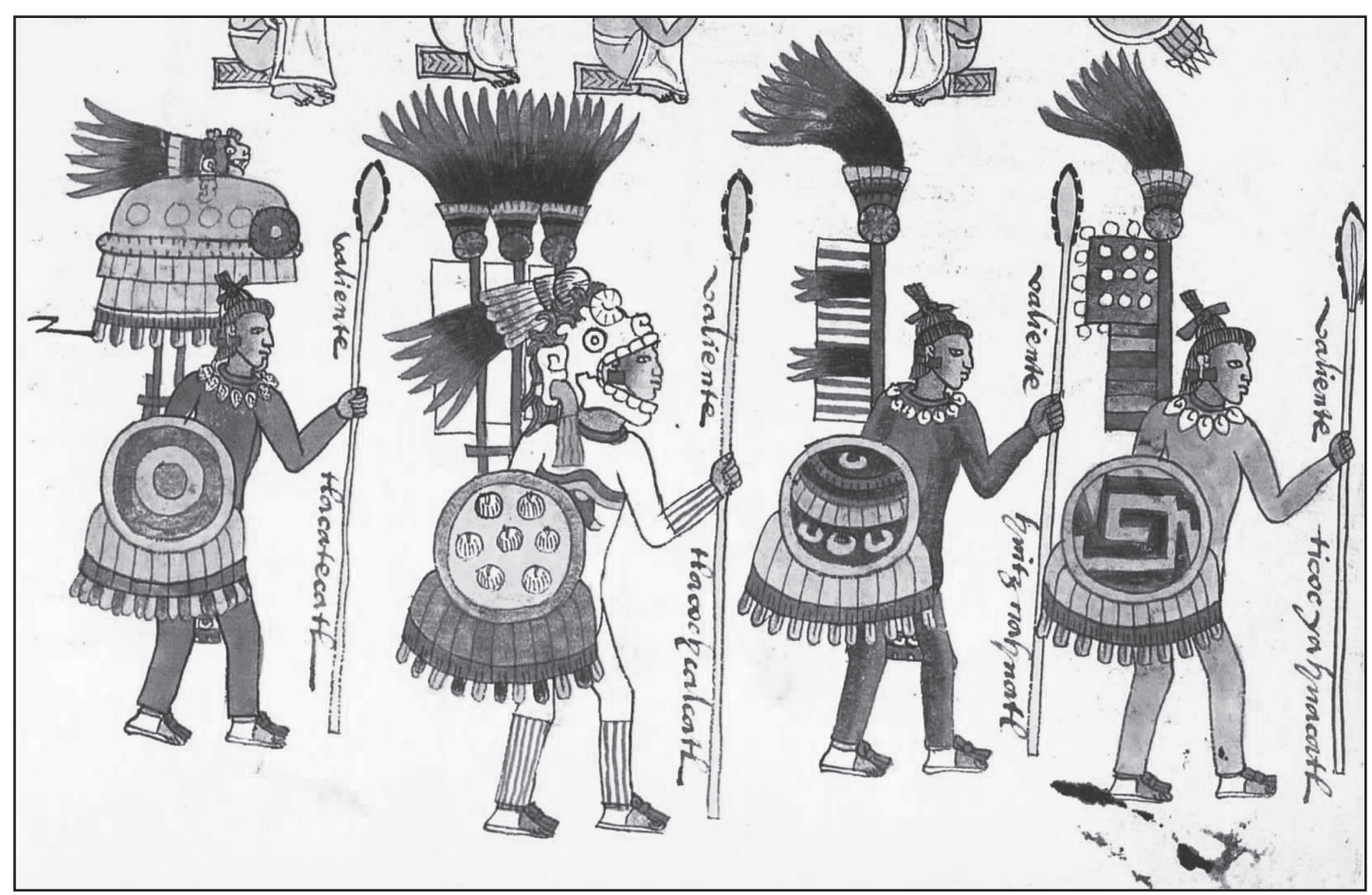

Figura 1. Códice Mendoza folio 67r. Biblioteca Bodleian, Universidad de Oxford.

mexica se la llamó ideología mística guerrera. Pero, independientemente de los calificativos, la ideología de Estado propugnaba que la mejor opción para el hombre mesoamericano era servir a su comunidad como guerrero. Obtenía beneficios económicos y reconocimiento social $\mathrm{y}$, además, le tranquilizaba al ofrecerle también una muerte mejor, una muerte afortunada o xuchimiquiztli.

La estrategia y la táctica se desarrollan en función de las armas disponibles. En Mesoamérica las principales eran la honda, el arco, las flechas, el átlatl y el macuáhuitl. La introducción del arco y las flechas por los mexica en el largo conflicto chalca, durante el reinado Moctezuma I, ilustra perfectamente esta afirmación: se relegó a un segundo término el combate cuerpo a cuerpo en favor del arco y las flechas, con la consecuencia de la muerte indiscriminada y el ascenso social de los guerreros que no pertenecían a la elite militar.

Varios cuerpos formaban el ejército mexica: los soldados de bulto, que utilizaban hondas, arcos y flechas, y los de elite, especializados en los combates cuerpo a cuerpo con sus potentes macuáhuitl, el arma genuinamente mesoamericana (Cervera, 2007: 61), como los cuauhuehuetl, los quachic o los ótomitl, algunos de ellos pertenecían a las órdenes totémicas. Juntos esperaban en formación a que la música marcara el inicio del ataque y toda vez que éste comenzaba debían prestar atención a su estandarte para la reagrupación o la retirada.

En el combate se podía distinguir a cada uno de los jefes en medio de la refriega gracias al emblema y a la bandera fijados a su espalda, confecciones frágiles y preciosas de cañas y de plumas; de pedrería y oro; cada una de estas insignias tenía su nombre protector confeccionada en gruesas fibras de algodón (Zagoya, 2000: 18). 
Para conquistar la plaza se utilizaba el asedio, la emboscada, el ataque directo y las guerras floridas, que han sido las que más atención han merecido, quizá porque con ellas se relacionan los sacrificios humanos. Actualmente, el estricto significado ritual que se le suponía queda en un segundo plano frente a las motivaciones políticas, integrándolas como parte de una guerra de conquista. Para estos combates se pactaba el lugar y allí se reunían con el mismo número de combatientes, hasta que se agotaba uno de los dos bandos. Se pretendía minar el poder del contrario, sin llegar a una guerra total, mucho más costosa para el Estado mexica.

Había otros tipos de estrategias - que, en lenguaje moderno, podríamos denominar guerra psicológica-, a través de los cuerpos pintados, los gritos y la música atronadora e incesante que no permitían ni la concentración, ni el descanso del enemigo; y la guerra química, envenenando el agua o usando panales cargados de avispas o fardos de chiles ardiendo, que obligaban al enemigo a salir de su escondite.

En esta compleja organización no podían faltar ni las guarniciones, diseminadas por todos los puntos fronterizos y conflictivos del imperio, ni un buen servicio de inteligencia gracias al cual, meses antes de emprender la marcha, los espías habían llevado a Tenochtitlan la información para desarrollar la estrategia de la batalla.

Los prisioneros de guerra se llevaban a Tenochtitlan y allí permanecían hasta el día de la celebración de la fiesta de tlacaxipehualiztli en la que se realizaba el sacrificio «a manera de gladiatores romanos» (Muñoz Camargo, 2002: 146) (fig. 2).

Este rápido repaso ofrece una visión muy sucinta de la complejidad de la guerra entre los mexica, con sus implicaciones políticas ${ }^{1}$, y nos sitúa en el momento de las celebraciones.

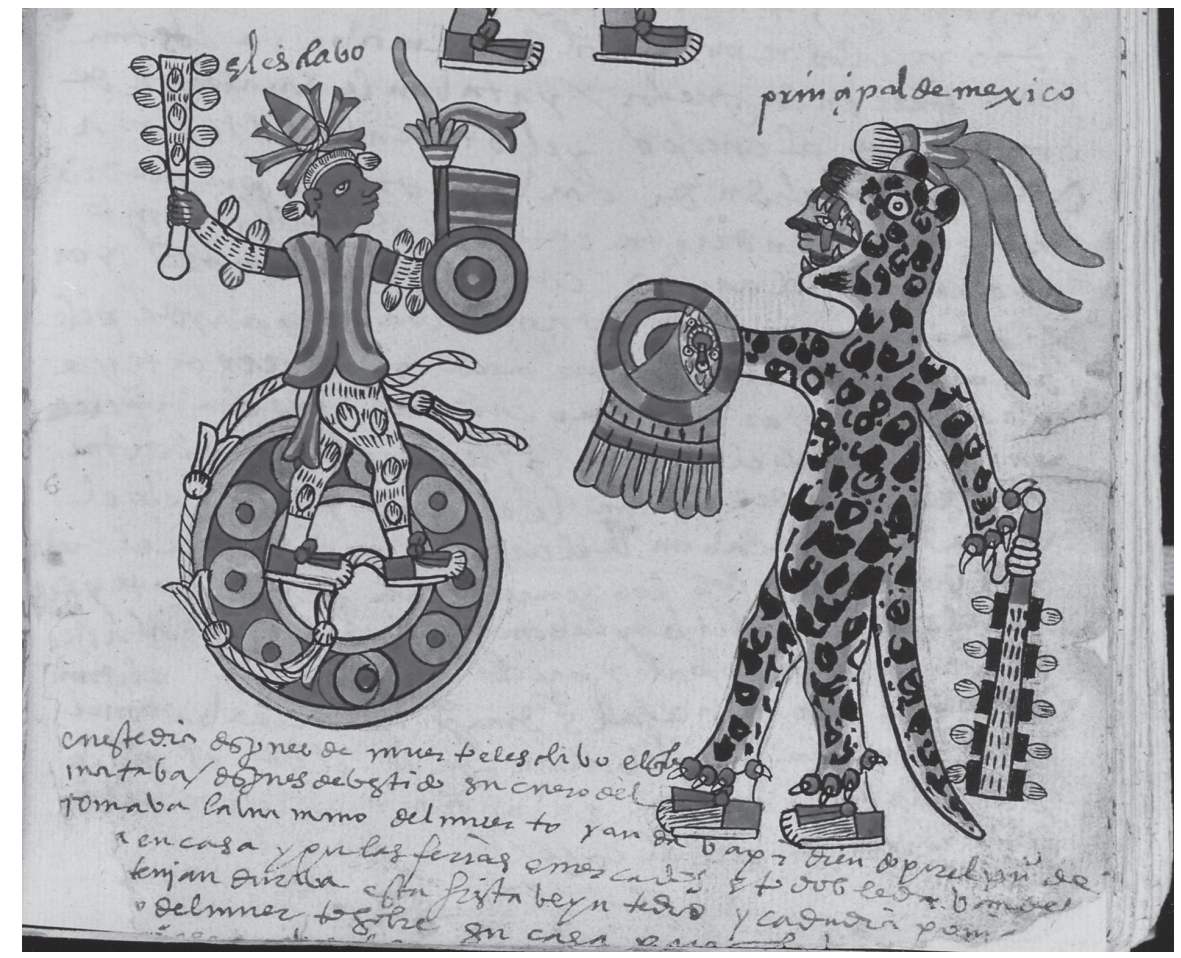

Figura 2. Códice Tudela folio 12r. Museo de América, Madrid.

1 Para profundizar en estos aspectos v. Bueno, 2007. 


\section{GUERRA, CEREMONIAL Y SACRIFICIO PÚBLICO}

Los espectáculos de masas fueron fomentados por el imperio mexicano para hacer ostentación de su poder y controlar a las comunidades, haciéndolas partícipes y cómplices. Estas celebraciones implicaban sacrificios humanos, un hecho que hace posicionarse incómodamente al investigador. Hay quienes se afanan en negarlos y otros tratan de maquillarlos o de exagerarlos, en función de sus propios intereses y de sus convicciones religiosas.

La documentación mesoamericana, pre y poscolonial, ofrece, a todo color, un catálogo detallado de sacrificios que los hace innegable; reciben distintas denominaciones, pero, al fin y al cabo, sangre en la arena, en nombre de dioses o de hombres sedientos del rojo vital. Un éxtasis que la comunidad compartía, deseaba y disfrutaba. Pero ¿cuáles eran sus motivaciones?

Recientes hallazgos en la cosmopolita y refinada ciudad de Teotihuacan muestran la práctica del sacrificio humano, exculpando a los mexica de introducir esta costumbre en Mesoamérica (Taube, 2004: 170). Yolotl González (1985: 212), basándose en la Historia tolteca-chichimeca, sitúa su origen «en el momento en que los toltecas fueron a Chicomóztoc a buscar a las tribus chichimecas y las invitaron a sacrificar»; a partir de ese momento y durante la peregrinación las fuentes muestran distintos instantes que implican a acolhuas y a otros pueblos mesoamericanos en los sacrificios humanos; los mexica, al entrar en contacto con ellos, adoptaron este uso.

Durán (1967, II, [cap. IV]: 41-42) relata el «contratiempo» que tuvieron los mexica con la moza princesa de Culhuacan cuando vivían en Tizapán; también sabemos por las fuentes que la fundación de Tenochtitlan está vinculada al sacrificio y a la extracción del corazón de Copil, así como la Historia de los mexicanos y los Anales de Tlatelolco confirman la realización de sacrificios en Tenochtitlan cuando eran subordinados de Azcapotzalco. De estos datos parece desprenderse que el sacrificio humano entre los mexica guarda relación con su establecimiento en la Cuenca de México. Como vasallos de Azcapotzalco hasta 1428 adoptaron usos y costumbres de los que allí vivían para su integración político-administrativa, pero ¿estos datos permiten afirmar que los sacrificios humanos los adoptaron por aculturación?

Asumieron aspectos políticos y religiosos para ser aceptados (López Austin, 1981: 69), entre ellos un calendario solar, vinculado a los ciclos agrícolas, repleto de celebraciones y de dioses a los que había que honrar (fig. 3). Éstos exigían el líquido de la vida y el último pálpito del rojo jade.

Lo que denota claramente el papel de la religión como instrumento del grupo dominante, como la forma de dominación ideológica, es el enorme ceremonial enmarcado dentro del calendario (González, 1985: 103).

El sacrificio era una deuda antigua que el hombre había contraído con los dioses (Graulich, 2003: 19) y éste, a través de las ceremonias, se afanaba por satisfacerla. En el calendario hay multitud de fiestas y en cada una de ellas la imaginación de los mexica se dejaba volar, y así, aunque la extracción del corazón es el sacrificio que relacionamos con ellos, no faltaban otras modalidades como el flechamiento o el desollamiento, que era un rito postsacrificial. Todos ellos actos públicos que congregaban a multitud de espectadores de todas las provincias (Tezozomoc, 2001, [cap. LXXII]: 306).

... constituía un gran espectáculo para los habitantes de Tenochtitlan y de sus alrededores, exaltándose el carácter guerrero de los mexicas, pregonando y alabando el valor de los participantes guerreros cautivos y de los ofrendantes (González, 1985: 223).

El calendario mexica estaba plagado de celebraciones en las que la sangre era un elemento imprescindible; conforme el imperio se extendió, hubo más que celebrar y, así, triunfo bélico 


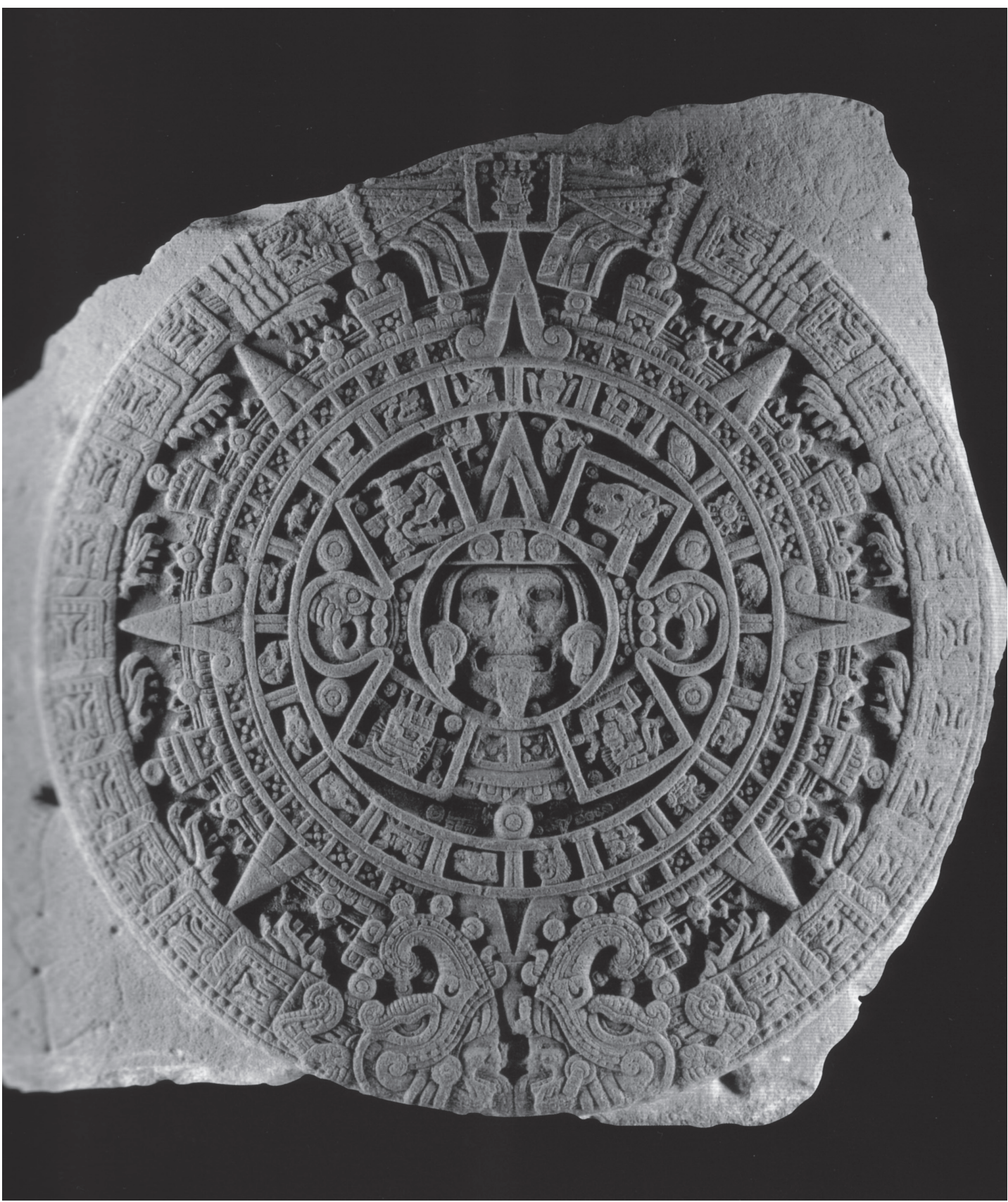

Figura 3. Piedra del Calendario. Museo Nacional de Antropología, México.

y celebración se retroalimentaron y se hicieron más complejos, de tal forma que los mexica fueron impregnando sus fiestas de un misticismo y ceremonial cada vez más barroco, hasta conseguir ser víctimas y no verdugos, merced a su ideología. Los dioses lo exigían, se sacrificaron con anterioridad en Teotihuacan, para que la vida fuera posible. Los mexica eran solamente un pobre pueblo, abrumado por la responsabilidad, y la única forma de tener engrasada la maquinaria cósmica era cumplir con el ritual. 
Todas estas ceremonias necesitaban un espacio apropiado con dimensiones monumentales para acoger a una enorme cantidad de espectadores, donde el régimen desplegaba su magnificencia y poder.

\subsection{El EPICENTRO IDEOLÓGICO}

Las celebraciones congregaban multitudes y los tlatoque pronto advirtieron el poder que ejercían controlándolas. Se concibieron espacios donde reunir al mayor número de espectadores receptivos al plan propagandístico y, para ello, el concepto espacial mesoamericano era idóneo con sus enormes plazas.

Hasta el reinado de Moctezuma I no se sistematizaron las celebraciones, a través de una meditada ideología, que se plasmó en un calendario al servicio del régimen imperial.

En un Estado centralizado el sacrificio se convierte, con su función reguladora y controladora de la violencia, en un medio de manipulación y de obtención de poder político a través del manejo de la ideología y de las fuerzas sobrenaturales (González, 1985: 36).

Aunque el gobierno mexica prácticamente monopolizaba las celebraciones en las que se ofrecían cautivos para el sacrificio, algunos miembros de las capas altas de la sociedad pudieron emular a los tlatoque, sobre todo guerreros y pochtecas que sacrificaban en honor de los dioses, para ser «reputados entre los magnates de la tierra» (Durán, 1967, I, [cap. VI]: 68).

El Estado mexica invertía en las celebraciones sobre seguro, ya que con el mínimo esfuerzo trasmitía los beneficios del sistema y la idoneidad de su liderazgo al numerosísimo público congregado. Su liberalidad conseguía la lealtad del pueblo en forma de apoyo político.

Políticamente había motivos más que suficientes para invertir en lo que Wells (1986: 252), refiriéndose a Roma, denominó teatro del terror, y por eso no se escatimó en ofrecer espacios cada vez más grandes y fastuosos donde mostrar la fragilidad de la vida y el arbitrio del poder.

El escenario mesoamericano satisfacía a la perfección los deseos megalómanos del régimen imperial. El lugar destinado a las celebraciones públicas era sagrado, un axis mundi en el que confluía la energía cósmica y donde dioses y hombres se comunicaban al rememorar mitos ancestrales; de él partían las avenidas orientadas hacia los cuatro rumbos del Universo; cosmograma que Taube (2004: 175) observa que se repetía en la escenografía formada por los cuatro sacerdotes que sujetaban a la víctima en la extracción del corazón.

Era un escenario en el que no faltaba la teatralidad monumental que derrotaba al espectador, pirámides con escalinatas imposibles, cuya verticalidad desafiaba las leyes de la gravedad, coronadas con templos enigmáticos frente a los que se recortaba la téchcatl, cuyo vértice recibía como un imán la espalda del cautivo; las enormes temalácatl, plataformas circulares ricamente decoradas con las victorias más gloriosas, sobre las que el «gladiador» perdía su última batalla (fig. 4); la cancha de tlachtli, donde la vida y la muerte rebotaban al ritmo del ollin; braseros cuyo claroscuro los cubría de misterio mientras exhalaban el aroma del copal $\mathrm{y}$, por supuesto, los tzompantli, esas estructuras de piedra y madera donde se colocaban los cráneos-trofeo del Estado, expresión gráfica y literal del poder político.

Respecto al origen de los tzompantli los investigadores no se ponen de acuerdo, hay quien los sitúa en el área mexicana de Chalchihuites (Hers, 1989; López Austin y López Luján, 1999: 31-32) y quienes lo hacen en tierras mayas (Graulich, 2002: 108). Independientemente de esta polémica, de lo que no cabe duda es que contemplarlo conseguía sus objetivos, no hay más que leer la honda impresión que causó a los españoles (Tapia, 2002: 105). 


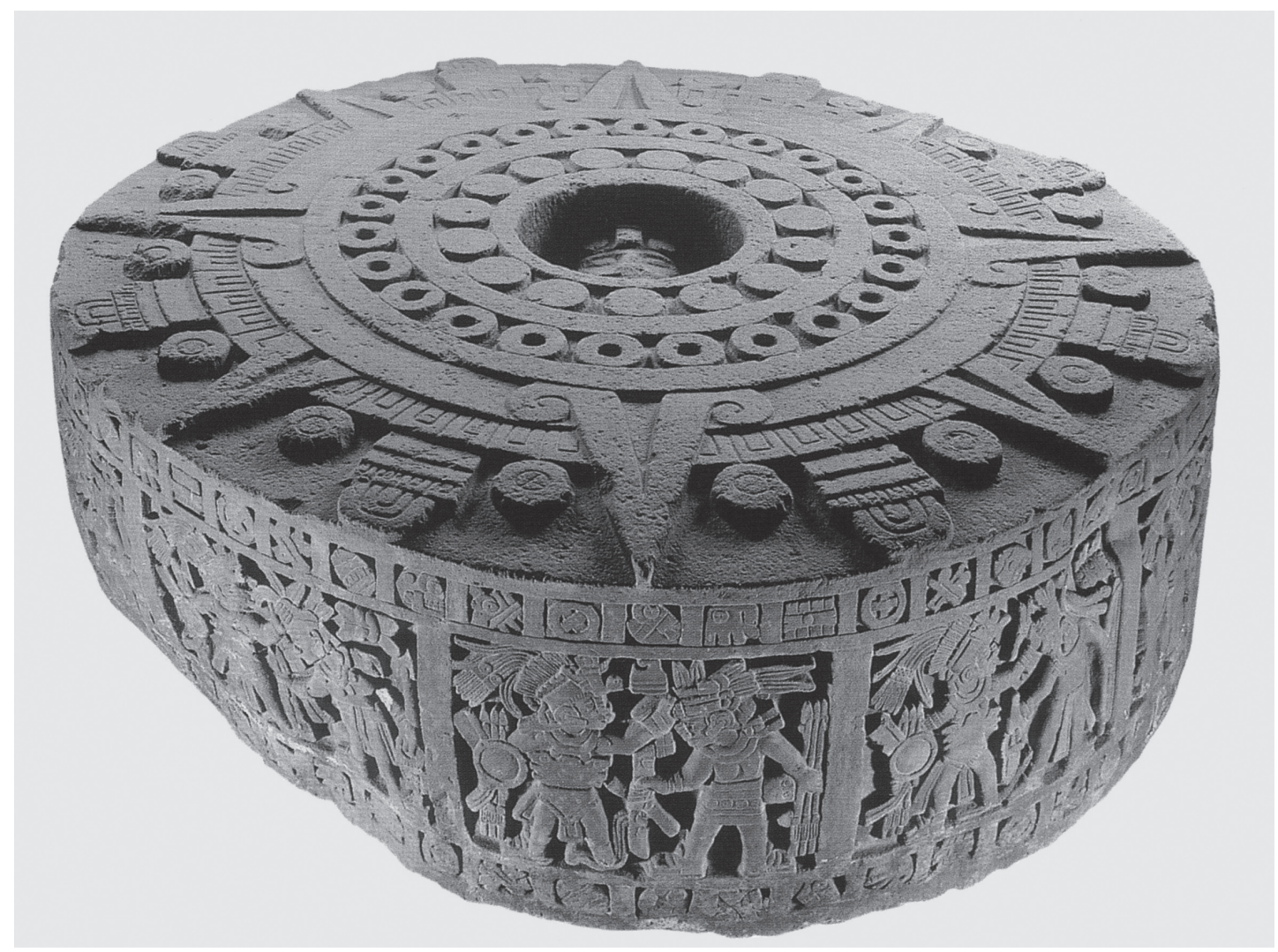

Figura 4. Piedra de Moctezuma I. Museo Nacional de Antropología, México.

La utilidad del tzompantli empezaba una vez realizado el sacrificio, entonces el cuerpo se devolvía al oferente, excepto la cabeza, que pertenecía al Estado y que públicamente se exponía en el tzompantli, pues la función de este altar-ábaco era mantener vivo el terror en los que pertenecían al imperio y los que permanecían independientes, pero que habían sido invitados a la fiesta de Tlacaxipehualiztli (Durán, 1967, II, [cap. XX]: 174).

Los tzompantli, al pie de los templos de Tenochtitlan, prolongan para uso de los numerosos visitantes extranjeros el efecto disuasivo de los sacrificios: recuerdan espectacularmente la inquebrantable y permanente determinación de ejercer el poder sobre todo el centro de México (Duverger, 1983: 177).

En ese extraordinario escenario los sacerdotes, con sus mejores galas y afilados cuchillos de pedernal; guerreros transmutados en sus nahualli; la propia víctima, que también era el doble del dios o del gobernante, para que murieran y nacieran a través de ella; la música, el ayuno, la vigilia, el alcohol y los hongos tóxicos remataban la puesta en escena, transportaban a un espacio y a un tiempo cero, donde todo estaba en calma: orden en el cosmos, otro estado de consciencia que ayudaba a la víctima y al verdugo (Durán, 1967, I, [cap. IX]: 98).

Pero las celebraciones no estaban completas sin los espectadores. Miles de personas se congregaban para ver los imponentes ritos públicos $\mathrm{y}$, a veces, para participar en ellos activamente (Durán, 1967, I, [cap.IX]: 97), aunque había otra forma de participación más importante: su aquiescencia en la aceptación de las normas, de tal forma que el asesinato ejercido por el 
Estado dejaba de serlo para convertirse en un acto sagrado. El tlatoani no escatimaba en gastos y su liberalidad quedaba más que probada en la puesta en escena y en el reparto de regalos (Durán, 1967, I, [cap. IX]: 99; Olivier, 2004: 196):

el sacrificio es, por tanto, un esfuerzo comunitario. Mediante la guerra y la fiesta, permite al pueblo entero asociarse a la gestión sagrada del cosmos (Duverger, 1983: 99).

la espectacularidad y el carácter comunal de los sacrificios mexicas eran sus características más importantes (González, 1985: 103).

En estos escenarios los luchadores dejaban su vida para regocijo del público, contento de los dioses y tranquilidad del imperio.

\section{LOS GUERREROS Y SU PREPARACIÓN}

Aunque Muñoz Camargo (2002: 146) afirmaba que los guerreros en las ceremonias luchaban como gladiadores romanos, el término gladiador procede del latín gladius en alusión al arma que utilizaban y, a pesar de que algunos gladiadores romanos alcanzaron notable fama, su procedencia y estima social eran bajas, porque solían ser prisioneros de guerra que se vendían como esclavos. Los «gladiadores» mexica, en muchos casos, también eran prisioneros de guerra, pero tenían una alta consideración y su arma, naturalmente, no era una espada, sino un macuáhuitl con afiladas navajas de obsidiana.

Había por lo menos dos variedades: el famoso macuáhuitl de cerca de 70 a $80 \mathrm{~cm}$ de largo, provisto de por lo menos seis a ocho navajas por lado, y el macuahuilzoctli, de cerca de $50 \mathrm{~cm}$ de largo y con unas cuatro navajas por lado. Es probable que la primera sea aquella a la que los españoles llamaron «de a dos manos», pues la equiparaban con su famosa espada mandoble o montante, usada efectivamente con las dos manos (Cervera, 2007: 61).

Los guerreros mexica eran extraordinariamente recompensados con mantas, armas, divisas, joyas, exención de tributos, práctica de la poliginia y, lo más importante, eran distinguidos con el afecto del tlatoani, abriéndoseles insospechadas parcelas de poder (Durán, 1967, II, [cap. LVIII]: 443). Pero antes de tan clamoroso éxito el guerrero mexica debía pasar un arduo entrenamiento en el telpochcalli.

\subsection{El TELPOCHCALLI}

Los mexica recibían su entrenamiento en el telpochcalli, la escuela obligatoria a la que asistían los jóvenes de toda consideración social desde alrededor de los 15 hasta los 20 años, edad en la que se licenciaban y entraban a formar parte de la edad adulta (Sahagún, 2001, II, [lib. 8, cap. 20]: 683). El instructor, un veterano de guerra, les adiestraba en el manejo de las armas: hondas, arcos, átlatl, cuchillos, lanzas, quauhololli y macuáhuitl. Además del entrenamiento, la alimentación a base de cereales y legumbres era fundamental para desarrollar la musculatura necesaria que permitía manejar las pesadas armas.

Los combatientes mexica recibían nombres diferentes que venían definidos por el número de capturas en la batalla: el cuextecatl era el guerrero que había capturado a dos enemigos en batalla y su traje era rojo, azul y amarillo, llevaba nariguera de oro y tocado con una insignia circular; el patzactli era el traje con faldón de plumas y penacho con plumas rojas y verdes; 
el tzitzimitl llevaba un espectacular tocado que representaba una calavera por cuyas fauces se asomaba la cabeza del guerrero, rematado con una concha y plumas verdes, el traje podía ser blanco, azul o amarillo y en el pecho llevaba el dibujo de un corazón; el quaxolotl, traje sobrio que contrastaba con el casco de plumas ricamente decorado; el ocelotl, traje y casco que imitaban al jaguar, era un guerrero que había capturado a cuatro enemigos; el momoyactli, el traje era parecido al del patzactli y había capturado cinco guerreros; el tozcoyotl había capturado seis enemigos; el matlaxopilli, cinco o seis; el papalotlahuiztli era una divisa para los guerreros que habían capturado a tres enemigos; el teocuitlacopilli era una variante del cuextecatl que se diferenciaba por la forma del tocado, que era achatado; el quetzaltototl y el tozcololli, cuyas divisas se confeccionaban con las exclusivas plumas de quetzal (Zagoya, 2000: 14-21) (fig. 5).

Independientemente de la especialidad de los combatientes, si eran zurdos o ambidiestros era una cualidad añadida que les hacía más temidos y reputados. En México algunos guerreros eran entrenados para utilizar el macuáhuitl con las dos manos. Estos especialistas tenían la misión de rayar al cautivo del combate gladiatorio cuando los cuatro guerreros águila y jaguar no lo habían conseguido (Durán, 1967 I, [cap. IX]: 98):

Algunos captivos que eran valientes cansavan a los cuatro peleando y no le podían rendir. Luego venía otro quinto, que era izquierdo, el cual usava de la mano izquierda por derecha; éste le rendía y quitava las armas y dava con él en tierra (Sahagún, 2001, I, [lib. II, cap. 21]: 150).

En las escuelas, además de los entrenadores, los masajistas y los cocineros, los cirujanos tenían un papel importantísimo, especializándose en las heridas que producían las armas (Cohen, 2003: 30). En México recibían el nombre de texoxotlaticitl (Lameiras, 1994: 73) y su profesionalidad fue destacada por los españoles, que los preferían a los médicos europeos (Torquemada, 1969, II, [lib. 14, cap. III]: 539). Podemos afirmar que las ceremonias con sacrificios fueron muy positivas para el avance de la medicina, ya que permitieron estudiar la anatomía con precisión y los médicos pudieron poner estos conocimientos a disposición de los pacientes, no sólo en el campo de batalla.

Finalizada la contienda, la suerte era dispar para los guerreros: muchos morían, otros eran heridos o hechos prisioneros, pero los que volvían victoriosos y con capturas eran recibidos como auténticos héroes y aclamados por la multitud, que esperaba disfrutar en las celebraciones del éxito de la batalla, especialmente con el combate gladiatorio.

Días antes de su llegada a Tenochtitlan los mensajeros habían traído al tlatoani las buenas nuevas, lo que permitía aderezar las calzadas para recibir a los héroes acompañados de sus cautivos. Valiosos tributos para honrar a los dioses en la fiesta del desollamiento. Esta celebración reivindicaba la necesidad de los guerreros para la sociedad y exaltaba su poder. Tenía lugar en el segundo mes de su calendario solar, coincidiendo con el equinoccio de primavera (Durán, 1967, I, [cap.V]: 243) y recibía el nombre de tlacaxipehualiztli. Era una celebración magnífica, que duraba varios días y, junto con el juego de pelota, era el espectáculo preferido del público, que congregaba a gentes venidas de todas partes del imperio:

Hallábanse á este sacrificio mucha más gente que a los demás [tlacaxipehualiztli o sacrificio gladiatorio], porque como [era] cosa famosa de hombres valientes que en él morían, concurrían de todas partes a verle (Pomar, 1991: 44).

En estos actos multitudinarios se ponía de manifiesto la diferenciación social y transgredir sus normas se penalizaba duramente. Además de ser un vehículo magnífico para difundir la propaganda política y buscar el consenso social (Clavel-Lèvéque, 1984). 


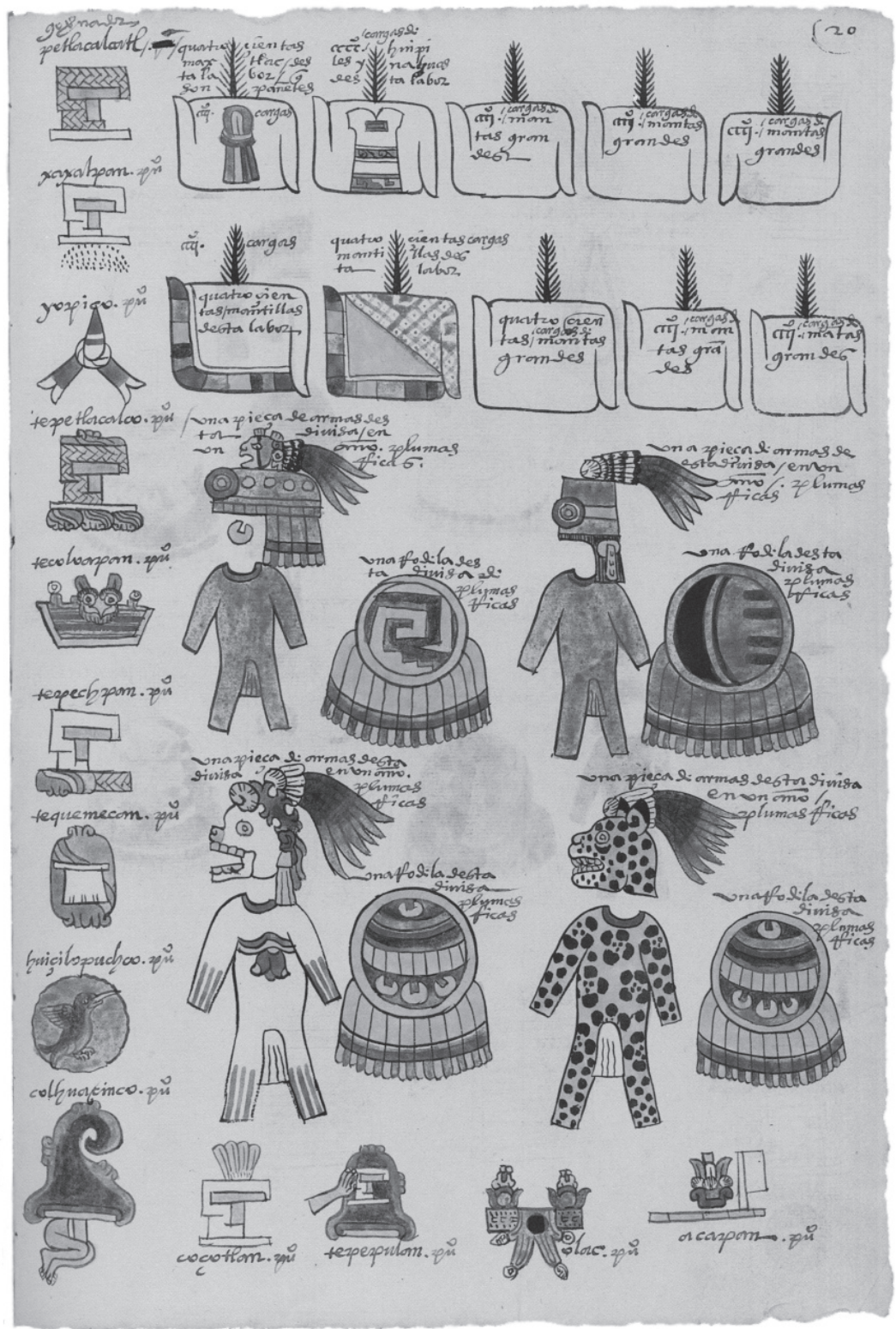

Figura 5. Códice Mendoza folio 20r. Biblioteca Bodleian, Universidad de Oxford.

Los ritos eran una necesidad colectiva y un instrumento de control de los jerarcas hacia la sociedad. Eran también un instrumento de poder y excusa para dominar a terceros (Cue, 1995: 67).

En la celebración de la victoria se premiaba generosamente a los guerreros que se habían distinguido en la batalla, después debían respetar cuarenta días de ayunos y penitencias, finalizados los cuales

eran llevados al Templo Mayor [...] Les horadaban las narices, labios y orejas, y la sangre que de ellos salía la ofrecían a sus dioses. [...] Poníanles en las orejas orejeras de oro y bezotes 
de lo mismo, y en las narices se ponían piedras ricas. Allí les daban públicamente sus arcos, flechas y macanas y todo género de armas usadas en su arte militar. Del templo eran llevados por las calles y plazas acostumbradas con gran pompa, regocijo y solemnidad (Muñoz Camargo, 2002: 95).

Los guerreros destacaban entre la muchedumbre con sus vistosos trajes y sus sofisticados penachos, confeccionados con pieles y hermosas plumas, cuyo número y color marcaba el rango. Todos los materiales venían de tierras lejanas y se conseguían a través de las obligaciones fiscales que Tenochtitlan exigía a sus provincias, aunque, a veces, los trajes militares se exigían ya confeccionados, como reflejan el códice Mendoza o la Matrícula de Tributos (fig. 6).

A pesar de que las insignias y las divisas ordenaban el escalafón militar y que las fuentes ofrecen nombres variados, sólo el Mendoza distingue doce tipos de uniformes y no queda claro el orden de importancia. Por ejemplo, el tlacateccatl y el tlacochcalcatl eran los guerreros de más graduación, pero no se puede deducir cuál era superior. El hecho de que los tlatoque alcanzaban el rango de tlacateccatl podía ser una pista que nos indique un rango mayor que el de tlacochcalcatl, aunque no concluyente, pero sin duda el apoyo que recibían del ejército como tlacateccatl era decisivo para alcanzar el cargo de tlatoani (Chimalpahin, 1965, [3. ${ }^{a}$ Relación]: 91, 118; [7. ${ }^{a}$ Relación]: 189; Rounds, 1982: 77).

\subsection{GRANDES LUCHADORES}

Los guerreros que más destacaban eran megaestrellas aclamadas por la sociedad y mimadas por los poderosos, hasta tal punto que quedaron inmortalizados en el arte y en las fuentes escritas. De los nombres que conocemos, quizá el luchador más representativo fue el otomí Tlahuicole $^{2}$ (Tezozomoc, 2001: 432), que vivió durante el reinado de Moctezuma Xocoyotzin.

Fue tan esforzado y valiente que, con sólo oír su nombre, sus enemigos huían de él. Fue de tan grandes fuerzas que la macana con que peleaba tenía un hombre bien que hacer en alzarla. Este quiere decir que no fue alto de cuerpo, sino bajo y espaldudo, de terribles y muy grandes fuerzas, que hizo hazañas y hechos que parecen cosas increíbles y más que de hombre [...]. Finalmente, que al cabo de muchas hazañas y buenos hechos que hizo, le prendieron los huexotxincas atollado en un ciénaga y, por gran trofeo, lo llevaron enjaulado a presentadle a Moctheuzoma a México, donde le fue hecha mucha honra y se le dio libertad para que se volviese a su tierra, cosa jamás usada con ninguno (Muñoz Camargo, 2002: 148).

En líneas anteriores he afirmado que los guerreros tenían un código de honor según el cual, una vez apresados, no podían renunciar a su destino, ya que si huían no eran bien recibidos en su comunidad y si eran perdonados, tampoco; la única opción digna era combatir con valentía sobre la Tamalácatl. Sin embargo, hecha la ley hecha la trampa, pues también sabemos que apropiarse de un cautivo estaba penalizado con la muerte y que en caso de duda o disputa la causa se llevaba a juicio y bajo juramento se le preguntaba al cautivo. Aunque Sahagún (2001, II, [lib. 20, cap. VIII]: 683) afirma que un guerrero experimentado podía «ceder» su prisionero, a un joven noble que salía por primera vez, a cambio de «regalos».

En el caso de Tlahuicole, Moctezuma II rompió las reglas y le ofreció la libertad, pero el otomí rechazó la generosa oferta y el tlatoani decidió aprovechar las cualidades del prisionero en favor de su política exterior y le puso al frente de su ejército para ir contra los tarascos:

\footnotetext{
2 Sobre el origen de Tlahuicole no hay unanimidad: mientras unas fuentes, como Tezozomoc, afirman que era otomí, otras simplemente dicen que era un capitán tlaxcalteca.
} 


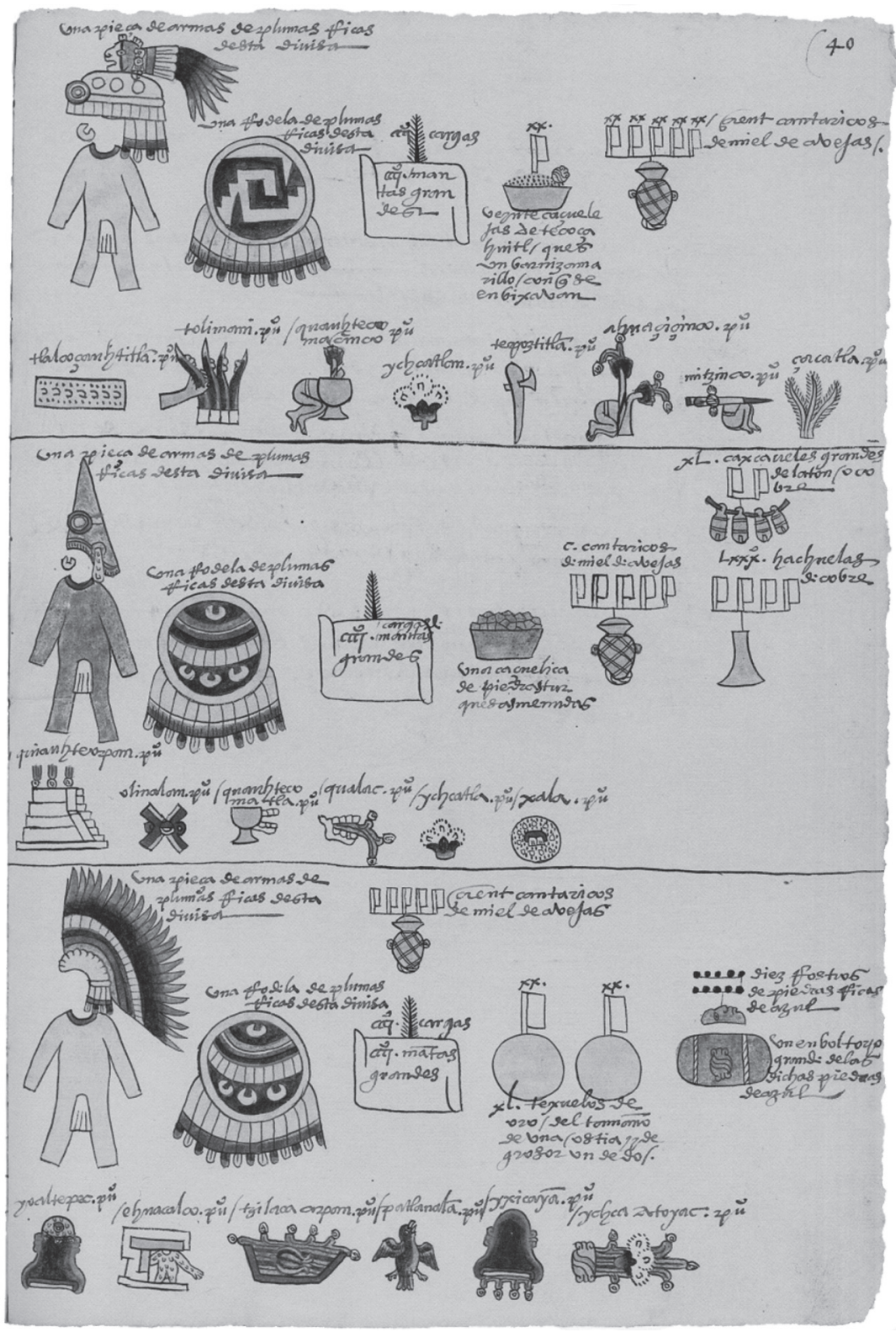

Figura 6. Tributos Códice Mendoza folio 40r. Biblioteca Bodleian, Universidad de Oxford.

Y ansí fue que, hecha una muy gruesa armada por los mexicanos, al dicho Tlahuicole, prisionero de Tlaxcala, se le encargó por parte de Moctheuzoma, la mayor parte de esta armada [...] en seis meses que duró la guerra, en la cual Tlahuicole hizo por su persona grandes hechos muy temerarios, [y] ganó entre los mexicanos eterna fama de valiente y extremado capitán (Muñoz Camargo, 2002: 148).

Cuando regresó a Tenochtitlan Moctezuma le reiteró su oferta, dándole a elegir volver a Tlaxcala o quedarse como capitán de sus ejércitos. Sin embargo, el valiente no aceptó, porque 
cualquiera de estas opciones le convertía en un traidor. Por ello, pidió a Moctezuma que «le hiciese merced de solemnizar su muerte, pues quería morir como lo acostumbraban hacer con los valientes hombres como él» (Muñoz Camargo, 2002: 149). Es decir, luchando en la Tamalácatl.

Moctezuma Xocoyotzin accedió y ordenó que se preparara todo para el combate gladiatorio y tras ocho días de fiestas y bailes (fig. 7).

El desventurado Tlahuicole fue atado en la rueda del sacrificio con mucha solemnidad, según sus ceremonias $[y]$, peleando, mató más de ocho hombres e hirió más de otros veinte antes que le acabasen de matar. Al fin, al punto que le derribaron, le llevaron ante Huizilopuhtli y allí le sacrificaron y sacaron el corazón, ofreciéndoselo al demonio, como lo tenían de costumbre (Muñoz Camargo, 2002: 148).

Tlahuicole alcanzó la inmortalidad, convirtiéndose en un afamado héroe todavía celebrado en Tlaxcala. Sin embargo, Tezozomoc (2001: 432-433) ofrece otro final menos valeroso: al parecer Tlahuicole lloraba amargamente en su presidio porque añoraba a su familia, enterado Moctezuma le pareció que era un acto de cobardía y que desprestigiaba a los guerreros y por ello ordenó que le dejaran libre para que se fuera a su tierra, desesperado por el desprecio del tlatoani Tlahuicole «fue a un cu alto de Tlatelolco y subido allá, despeñose de allá y murió».

De la biografía de Tlahuicole se desprende que un hombre del pueblo podía alcanzar gran prestigio social a través de sus logros en la guerra y que, a pesar de la rigidez de las leyes militares, éstas podían vulnerarse si beneficiaba a los intereses políticos.

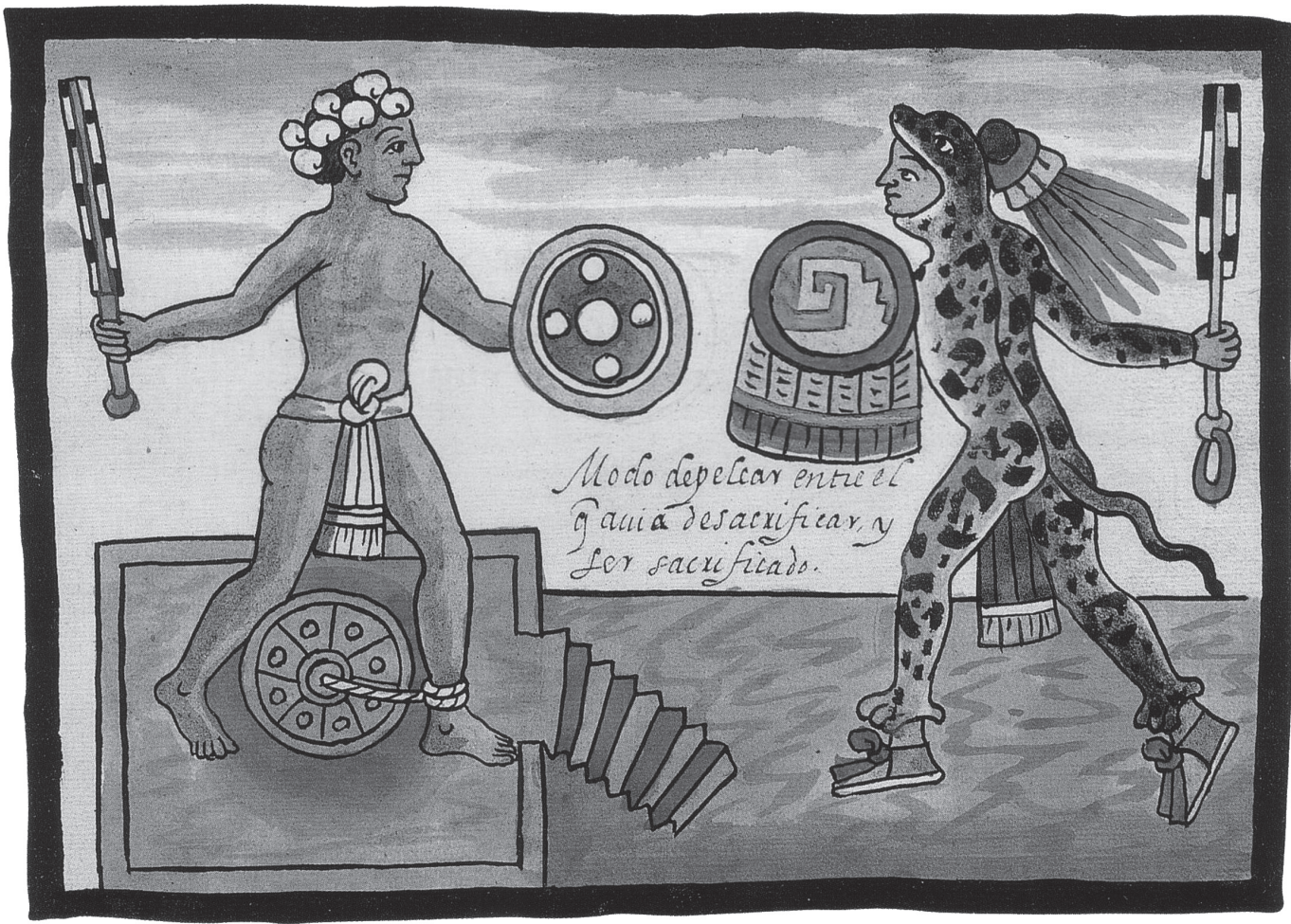

Figura 7. Manuscrito Tovar folio 134. Biblioteca John Carter Brown, Universidad Providence, Rhode Island. 


\section{TLACAXIPEHUALIZTLI O SACRIFICIO GLADIATORIO}

Es difícil discernir en las fuentes el origen del combate gladiatorio entre los mexica, éstas dejan constancia de que durante el reinado de Moctezuma I, su cihuacoatl Tlacaelel elaboró la ideología que envolvió la expansión del imperio, y los combates gladiatorios formaban parte de ella. «Porque este Tlacaelel, demás de ser valeroso y muy avisado en ardides de guerra, fue inventor endemoniado de sacrificios crueles y espantosos» (Durán, 1967, II, [cap. XX]: 171). Pero quizás, los antecedentes se encuentren en la sociedad tolteca. La Historia toltecachichimeca (1976: 84) afirma que el sacrificio gladiatorio o rayamiento lo practicaban los toltecas con los prisioneros de alto rango como los gobernantes y completaban el rayamiento con el flechamiento (González, 1985: 223).

Si es poco lo que las fuentes ofrecen sobre el origen del sacrificio gladiatorio, son algo más generosas en cuanto a su organización y puesta en escena: la celebración de tlacaxipehualiztli o rayamiento se realizaba en honor de Xipe-Totec, aunque Sahagún (2001, I, [lib. II, cap. 21]: 147) afirma que también se honraba a Huitzilopochtli. Era un espectáculo de enormes repercusiones políticas que convocaba a espectadores de todos los rincones del Anahuac, las fuentes mencionan que se invitaba incluso a los notables de las provincias sujetas al imperio y también a los líderes de las que permanecían independientes (Tezozomoc, 2001: 408).

El «rayamiento» era la culminación de los ritos guerreros; la gran prueba de valor individual que constituía el máximo espectáculo para el pueblo, el que acudía a ver luchar a sus mejores guerreros contra los mejores hombres de los enemigos, aunque éstos estuvieran en desventaja. El Estado promovía esta celebración, que era la reafirmación de la grandeza mexica (González, 1985: 228).

El sacrificio humano no es para los aztecas un acto místico en que la sociedad realizaba su propia oblación para la salvación del resto de la humanidad; por lo contrario, es una técnica de dominación que asegura el crecimiento del grupo a expensas de las poblaciones periféricas. Es necesario que los sacrificios sean ajenos al imperio mexicano para que la guerra, necesaria para su captura, pueda con el mismo impulso servir para extender el poderío azteca (Duverger, 1983: 213).

El pueblo esperaba impaciente que, con las primeras luces del día, comenzara la fiesta. Sin embargo, para los protagonistas había empezado cuarenta días antes: los guerreros, con ayunos y autosacrificios, y algunos de los que serían sacrificados eran purificados para que durante esos días representaran al dios Xipe (Durán, 1967, I, [cap. IX]: 96). En la medianoche del 20 al 21 de marzo los guerreros encendían una hoguera y a la luz de la lumbre arrancaban algunos cabellos de sus prisioneros que guardaban como reliquias-trofeo, porque ese cabello contenía el calor vital y el honor del sacrificado (Graulich, 2003: 23); después realizaban sus ofrendas de sangre para satisfacción de los dioses, tan asociadas a los guerreros.

$\mathrm{Al}$ alba del 21 de marzo al indígena que había representado al dios Xipe durante cuarenta días, y a otros que, como él, representaban a los principales dioses, se les practicaba el $s a$ crificio ordinario (Durán, 1967, I, [cap. IX]: 97). Éste consistía en que el sacrificador, con el corazón en la mano, se colocaba en un lugar llamado zacapan para que todos los que quisieran hicieran ofrendas de maíz. Terminadas éstas los sacrificados eran desollados como acto de regeneración, en un ritual postsacrificio.

Atados por cuerdas llamadas $<$ cuerdas de nuestra subsistencia $>0<$ de nuestro maíz $>$, los sacrificados eran asimilados con espigas de maíz y representaban la recolección, que era doble, para los hombres, en los campos y para los dioses. Como alimento del sol y de la tierra, se convertían en compañeros del águila. En cuanto a las pieles de las que se les despojaba — en honor 
de Xipe, especialmente dios de la penitencia - cuando se tornaban completamente repugnantes, representaban la estación y la suciedad pasadas (Graulich, 1990: 406).

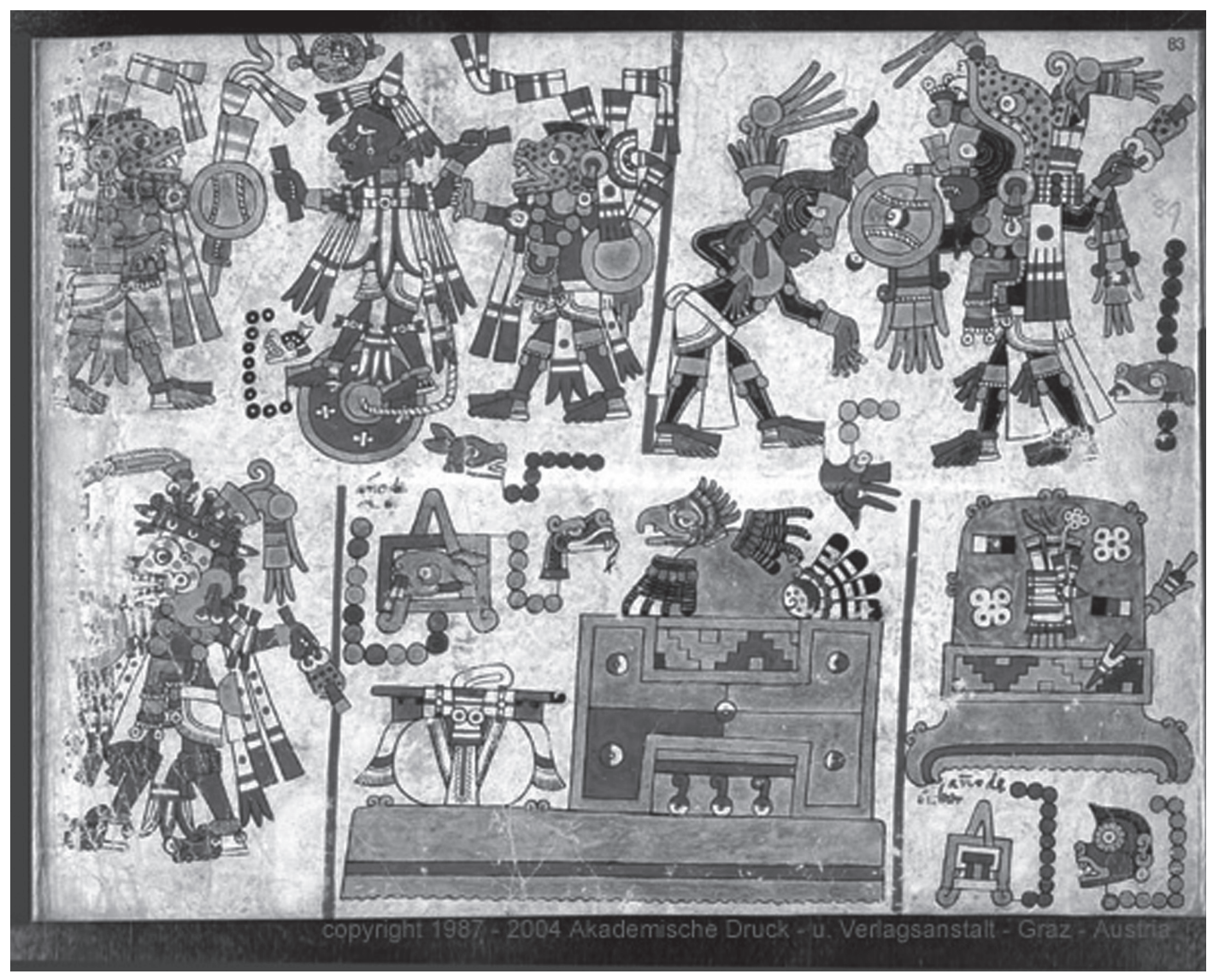

Figura 8. Códice Nuttall, folio 89. Museo Británico.

A continuación su piel era vestida por otros que se colocaban todos los atributos de los dioses. Quizás para formar parte del combate fingido que había después y que era un entretenimiento para el público y lucimiento de los participantes. El combate lo formaban dos bandos, uno que defendía los «colores» de Xipe y que eran los que vestían las pieles de los desollados recientes, y el otro bando estaba compuesto por guerreros, posiblemente del telpochcalli. (Durán, 1967, I, [cap. IX]: 97; Sahagún, 2001, I, [lib. I, cap. 18]: 79)

Tras el combate fingido, los que vestían las pieles e insignias de los dioses eran atados y conducidos a la zona del temalácatl, donde daba comienzo la siguiente y más esperada fase de la fiesta: el sacrificio gladiatorio. En procesión, al son del tambor, desfilaban muchos actores: los sacerdotes más importantes, los nobles, quienes representaban a los cuatro rumbos del universo y los cuatro guerreros, águilas y jaguares, armados con sus chimalli multicolores y afilados macuáhuitl, que se colocaban a los lados de los dioses vivientes (Durán, 1967, I, [cap. IX]: 98).

Cuando todos se acomodaban en los lugares establecidos salía el primer prisionero que, sobre el temalácatl, era atado por una pierna con la soga que salía del agujero central para reducir su movilidad. Le daban para beber alcohol sagrado, teooctli, que mitigaba su miedo 
y aumentaba su valor, pues tenía que enfrentarse a sus contrincantes con armas falsas y unas simples bolas de madera. Al son de la música y los cánticos empezaba el combate desigual y cuando el guerrero águila o jaguar le hería, le rayaba y brotaba la sangre, la música daba la señal para que el herido se tumbara en el suelo (fig. 8).

Ese sonido marcaba el momento de conducir al cautivo hacia el cuauhxicalli, donde el sacerdote le extraía el corazón y mano en alto «ofrecía al sol el vaho que de él salía» (Durán, 1967, II, [cap. XX]: 174). Acabado el sacrificio

sacerdotes y principales y los señores de los esclavos, començavan a dançar en su areito en rededor de la piedra donde havían muerto a los captivos. Y los señores de los captivos en el areito, dançando y cantando, llevavan las cabeças de los captivos asidas de los cabellos (Sahagún, 2001, I, [lib. II, cap.21]: 151).

Pero si, excepcionalmente, el prisionero había conseguido vencer a los cuatro guerreros, entonces debía enfrentarse a los que representaban a los rumbos o a las auroras que manejaban el macuáhuitl con ambas manos (Durán, 1967, I, [cap. IX]: 99). El hecho de que el cautivo desarmado lograra vencer a un guerrero águila o jaguar bien armado era muy celebrado por los espectadores, puesto que la categoría del prisionero repercutía en el prestigio de su captor. Los guerreros tenían un código de honor que no les permitía ni escapar, ni admitir el perdón:

eran los indios más valientes que se habían escogido a elección del rey, haciendo muchas averiguaciones y diligencias de esfuerzo y ánimo, porque si no eran tales no morían en el sacrificio de este ídolo (Pomar, 1991: 42).

De igual forma que si tenía un comportamiento poco digno restaba categoría al cautivador

Hallóse que muchos no quisieron gastar tiempo en esta vanidad, sino que luego se rendían a la muerte y sacrificio, con que hacían menos famosos a los que los habían preso y vencido, de manera que tanto cuanto más esfuerzo mostraban peleando en este sacrificio, tanto más fama de valiente cobraban los que en la guerra los habían vencido y preso y traído al sacrificio poniéndoles en tanta estimación cuanto de más valor se habían conocido en el prisionero, y era ésta una cosa tan deseada entre ellos que aunque había muchos indios que habían prendido en la guerra muchos enemigos, no llegaban a sacrificar ninguno en este sacrificio de Xipe, si como se ha dicho no era muy averiguado de ser valiente para la dignidad de este día (Pomar, 1991: 44).

En opinión de Yolotl González (1985: 224), participar en la celebración del combate gladiatorio era un honor que el tlatoani concedía o solicitaba y, basándose en el códice florentino, piensa que eran «guerreros sacerdotes pues se les denomina tetlenamacazque y tlamacazque». Durán (1967, II, [cap. XX]: 172, 175) añade que Moctezuma I había ordenado que en el telpochcalli «los más principales se ejercitaran en este sacrificio» pues asistirían a presenciarlo «todos los señores de las ciudades y provincias comarcanas» y los distinguía con recompensas de tal forma que «ninguno quedaba que no hiciese mercedes en semejantes fiestas y solemnidades».

En cada celebración ofrendaban cuarenta o cincuenta cautivos y sus pieles se guardaban en el templo de Xipe durante cuarenta días, pasados éstos se enterraban a los pies de la escalinata del templo, pero también se prestaban durante veinte días a «limosneros» que llevaban la piel por el día, pidiendo de puerta en puerta. Al cabo de los veinte días las ganancias obtenidas las compartían con el dueño de la piel. Transcurrido el tiempo establecido, los cueros se enterraban en una ceremonia en la que los guerreros bailaban con todas las recompensas que el rey les había ofrecido por sus capturas, e invitaban a un gran banquete donde repartían regalos y 
levantaban un poste en casa de los guerreros, para colgar el fémur del sacrificado, como blasón de su valentía. Éste era un trofeo-talismán que protegía al guerrero en el campo de batalla (Durán, 1967, I [cap. IX]: 99, 101).

La celebración de tlacaxipehualiztli no solo se realizaba en Tenochtitlan, la capital imperial, sino que también tenía lugar en otras provincias (Duverger, 1983:98). Era una manera de unificar y de mostrar su poder en las provincias más pequeñas, eran las «galas» del régimen para que todos compartieran y temieran el éxito del imperio ${ }^{3}$.

Los señores de las provincias y ciudades, admirados y asombrados de semejante sacrificio, partiéronse para sus provincias y pueblos, llenos de temor y espanto (Durán, 1967, II, [cap. $\mathrm{XX}]$ : 174).

\section{CONCLUSIONES}

Hacer un seguimiento del desarrollo y ocaso del combate gladiatorio es harto difícil. Está integrado en el ritual, y va alcanzando complejidad de acuerdo a la evolución política y la expansión del imperio. A finales del siglo XV y principios del siglo XVI estos espectáculos habían alcanzado su apogeo y el Estado mexicano no escatimaba en gastos.

a honra de la cual fiesta, hizo un gasto excesivo y muy costoso, con mucha liberalidad y generosidad, que dejó espantados a los forasteros, y muy contentos y ufanos a todos los señores y populares de la ciudad (Durán, 1967, II, [cap. XX]: 175).

En las celebraciones mesoamericanas la protagonista era la muerte. Constituían el lado oscuro de la conquista, en cuyo escenario sangriento se rememoraba el último triunfo del imperio. Era un hecho ensalzado que contaba con la aprobación de toda la comunidad, porque en este acto se reforzaba la identidad de la misma, ya que a través de estas representaciones experimentaban, ellos mismos, la gloria de la conquista.

Pero la abrupta llegada de los europeos puso punto final a todo el ceremonial indígena y se ocupó de condenar el paganismo y la idolatría, con métodos tan expeditivos como los que condenaba, en nombre de un nuevo dios.

\section{BIBLIOGRAFÍA}

Bueno, I. (2007): La guerra en el Imperio Azteca: Expansión, ideología y arte. Madrid, Complutense.

Cervera, M. (2007): «El macuáhuitl un arma del posclásico tardío en Mesoamérica». Arqueología Mexicana, 84: 60-65.

Chimalpahin Cuauhtlehuanitzin, F. (1965): Relaciones Originales de Chalco Amaquemecan. México, Fondo de Cultura Económica.

Clavel-LévêQue, M. (1984): L'empire en jeux. Espace symbolique et practique sociale dans le monde romain, Paris, CNRS.

Códice Mendoza (1979): Códice Mendocino, ed. de J. I. Echegaray. México, San Ángel Ediciones.

CoHen, R. (2003): Blandir la espada: Historia de los gladiadores, mosqueteros, samurai, espadachines y campeones olímpicos. Barcelona, Destino.

\footnotetext{
3 En el yacimiento de Cihuatan, en El Salvador, han visto la luz estructuras aztecas que remiten a la fiesta de tlacaxipehualiztli, como un basamento circular, una imagen de Xipe Totec y un guerrero jaguar, cuyas fauces vomitan la cabeza de un guerrero.
} 
Collier, G. A.; Rosaldo, R. I. y Wirth, J. D. (1982): The Inca and Aztec States 1400-1800. New York, Academic Press.

Cue, L. (1995): «El tiempo y los rituales». Dioses del Antiguo México (Catálogo, Antiguo Colegio de San Ildefonso). México, Equilibrista-Turner: 57-89.

Durán, D. (1967): Historia de la Indias de Nueva España e islas de Tierra Firme, ed. de A. M. Garibay. México, Porrúa, 2 vols.

DUverger, C. (1983): La flor letal: economía del sacrificio azteca. México, FCE.

ECKARDT, E. (2005): «Sangre en la arena: Historia y Mito de los Gladiadores». National Geographic, nov: $2-25$.

GonZÁLez, Y. (1985): El sacrificio humano entre los mexicas. México, FCE.

Graulich, M. (1990): Mitos y rituales del México antiguo. Madrid, Istmo.

Graulich, M. (2002): «Los reyes de Tollan». Revista Española de Antropología Americana, 32: 87-114

Graulich, M. (2003): «El sacrificio humano en Mesoamérica». Arqueología Mexicana, XI, 63: 18-23.

Hers, M. A. (1989): Los toltecas en tierra chichimecas. México, UNAM, Instituciones de Investigaciones Estéticas.

Historia Tolteca Chichimeca (1976): Historia Tolteca-Chichimeca, con estudios, cuadros y mapas de P. Kirchoff, L. Odena Güemes y L. Reyes García, paleografía y versión al español de L. Reyes García. México, Instituto Nacional de Antropología e Historia-CISINAH.

LAmeIRAS, J. (1994): El encuentro de la piedra y el acero. Zamora, Colegio de Michoacán.

López Austin, J. (1981): Tarascos y Mexicas. México, FCE.

López Austin, A. y López Luján, L. (1999): Mito y realidad de Zuyúa. México, FCE.

Muñoz CAmargo, D. (2002): Historia de Tlaxcala. Madrid, Dastin.

Olivier, G. (2004): «Dioses y rituales», F. Solis (ed.) El imperio azteca. México, Conaculta: 194-196.

Pomar, J. B. (1991): Relación de Texcoco, ed. de G. Vázquez. Madrid, Historia 16.

Rounds, J. (1982): «Dynastic Succession and the Centralization of Power in Tenochtitlan», en Collier, Rosaldo y Wirth, 1982: 63-89.

Sahagún, B. DE (2001): Historia General de las Cosas de Nueva España. Madrid, Dastin.

TAPIA, A. (2002): «Relación de algunas cosas de las que acaecieron al muy ilustre señor don Hernando Cortés, Marques del Valle, desde que se determinó ir a descubrir tierra en la tierra firme del mar Océano». G. VÁzQuez (ed.), La conquista de Tenochtitlan. Madrid, Dastin.

TAUBE, K. (2004): «La religión azteca: creación, sacrificio y renovación», F. Solis (ed.) El imperio azteca. México, Conaculta: 168-178.

Tezozomoc, H. (2001): Crónica Mexicana, ed. de G. Díaz Migoyo y G. Vázquez. Madrid, Dastin.

Torquemada, J. (1969): Monarquía indiana. México, Porrúa, 3 vols.

WeLLS, C. (1986): El imperio romano. Madrid, Taurus.

ZAGOYA, L. (2000): «Análisis de los trajes de guerreros y escudos representados en el códice mendocino». Actualidades arqueológicas, 24: 14-21.

Recibido: 08/10/2008

Aceptado: 11/03/2009 